\title{
Factors associated with self-medication in children and the decomposition of rural- urban disparities in China
}

\author{
Jingjing Ge ${ }^{1,2}$, Xiaxia Sun ${ }^{1,3}$, Hongdao Meng ${ }^{4}$, Punam Ghimire Risal ${ }^{4}$ and Danping Liu ${ }^{1 *}$
}

\begin{abstract}
Background: Self-medication in children is one of the greatest threats to children health in China.

Objectives: The purpose of this study was to examine the potential factors associated with self-medication in children and explore rural-urban disparities.

Methods: A total of 2798 children enrolled in the study. Informed consent was obtained from each primary caregiver following a detail explanation about the purpose of the study. Multivariable logistic regression analysis and Oaxaca-Blinder decomposition analysis were used.
\end{abstract}

Results: The results showed that $38.2 \%$ primary caregivers of rural areas self-medicated their children, compared to $18.7 \%$ of those in urban areas. The urban primary caregivers with college or above education were more likely to self-medicate their children, while rural primary caregivers with college or above education were less likely to selfmedicate their children. Children having unhealthy eating habits were more likely to have been self-medicated by their primary caregivers in urban and rural areas. Urban primary caregivers who spend more than $10 \mathrm{~min}$ from home to the nearest medical institution were more likely to self-medicate their children. In rural areas, children aged 3-6 years old, primary caregivers with monthly household income per capita of 1001-3000 Yuan, and children with chronic diseases are another set of enabling factors which impacted on self-medication. Unhealthy eating habits of children were the largest contributor to the rural-urban self-medication gap.

Conclusions: Children's factors explained the largest portion of the rural-urban difference in self-medication among children. The evidence presented in this study suggests that public health policies addressing rural-urban differences in children's factors could serve as an effective method for reducing rural-urban disparities in selfmedication among children.

Keywords: Self-medication, Children, Rural-urban disparities, China

\footnotetext{
* Correspondence: liudanping03@163.com

'Department of Health Related Behavior and Social Medicine, West China

School of Public Health and West China Fourth Hospital, Sichuan University, Chengdu, China

Full list of author information is available at the end of the article
}

(c) The Author(s). 2021 Open Access This article is licensed under a Creative Commons Attribution 4.0 International License, which permits use, sharing, adaptation, distribution and reproduction in any medium or format, as long as you give appropriate credit to the original author(s) and the source, provide a link to the Creative Commons licence, and indicate if changes were made. The images or other third party material in this article are included in the article's Creative Commons licence, unless indicated otherwise in a credit line to the material. If material is not included in the article's Creative Commons licence and your intended use is not permitted by statutory regulation or exceeds the permitted use, you will need to obtain permission directly from the copyright holder. To view a copy of this licence, visit http://creativecommons.org/licenses/by/4.0/. The Creative Commons Public Domain Dedication waiver (http://creativecommons.org/publicdomain/zero/1.0/) applies to the data made available in this article, unless otherwise stated in a credit line to the data. 


\section{Background}

The use of medicines by individuals to treat selfrecognized illnesses or symptoms is defined as selfmedication [1]. Self-medication includes several forms through which individuals themselves or the caregivers (for minors) decide, without medical evaluation, which medication they will use for symptom relief and treatment; it involves sharing drugs with other members of the family and social group, using leftovers from previous prescriptions or disrespecting the medical prescription either by prolonging or interrupting the dosage and the administration period prescribed [2]. Children are often given medicines by their primary caregivers. Selfmedicated medicines in children included antibiotics, cough and cold medicines (CCMs), vitamins, supplements, and so on [3-7].

Globally, self-medication in children is wide spread, with self-administering of antibiotics is most common with potential serious consequences. A study in Tetovo reported $86.6 \%$ of parents using antibiotics without doctors' prescription [3]. Regarding the other self-medicated medicines in children, Ylinen et al. revealed that the prevalence of the use of Over The Counter (OTC) medicines (excluding vitamins), vitamins, and complementary and alternative medicines (CAMs) in the preceding 2 days were $17.0,37.0$, and $11.0 \%$, respectively [6]. A study in Germany suggested that $25.2 \%$ of caregivers had selfmedicated their children or adolescents, vitamin preparations were most frequently used with a weighted user prevalence of $4.7 \%$, followed by CCMs (4.4\%) and analgesics (3.7\%) [7]. Therefore, the self-medicating behavior among primary caregivers of children warrant additional investigations.

In China, self-medication in children is at a critical trend. Although regulations that categorise drugs as prescription only and OTC in China, they are not adequately enforced [8]. Many prescription-only medicines can be purchased without a prescription, including antibiotics, sedatives, tranquillisers, stimulants, and pain relievers [9-11]. For example, Miao's research showed that $62.0 \%$ of parents in Jiangxi province of China had selfmedicated their children with antibiotics [4]. Li et al. reported that $35.1 \%$ of the parents had taken antibiotics to treat diarrhea of their children without any prescription [5]. Since 1982, China had defined the family planning as a basic national policy, advocating late childbirth, and fewer births, to dampen population growth. Therefore, China has appeared a large number of single-child families. Despite the relaxation of the one-child policy since 2015, the fertility rate of Chinese parents was still low, especially for women with higher educational level and urban family [12]. In the family of only-child, parents often are excessively anxious or worried about the health of the child. If they have difficulty accessing to general practitioners and hospitals, the parents will immediately give the child medicine without doctors' prescription when their child exhibits symptoms of illness [13].

Some pediatric medications, such as vitamin supplements, are safe if used correctly, i.e. according to the package insert. Nevertheless, parents may have incorrect knowledge about medications, which can lead to inappropriate medication use, thus cause serious damage to health. For example misuse of antibiotics increases the risk of antibiotic resistance [14], excessive vitamin use may increase the risk of cancer and cardiovascular disease $[15,16]$, misuse of traditional Chinese medicine may cause liver and kidney damage [17]. Aspirin, for example, should not be used in children under 12 months of age, otherwise, adverse drug reactions may occur - Reye syndrome is a lifethreatening adverse reaction to aspirin in young children [18]. The dose of children's medications is different from adults, such as accidental CCMs that have resulted in serious adverse cardiovascular events, these incidents included several infant deaths [19, 20].

The population of China accounts for one fifth of the world's population, and more than half of the Chinese population lives in rural areas. Individuals with higher education and higher income are usually experience better health [21], while rural people are generally less educated and have lower income levels. Moreover, most medical institutions are located in cities, so people living in rural areas have less access to medical services [22]. Therefore, primary caregivers in rural areas may be more likely to self-medicate their children. For example, using antibiotics without medical prescription was higher frequency in lower socio-economic areas [23]. Yu et al. found that parents living in villages were significantly associated with self -medication of children with antibiotics in China [4].

The difference between urban and rural areas in family caregiver self-medicated their children may contribute to rural-urban children health disparities in China. It is necessary to examine the potential factors of selfmedication among children and assessed the contribution of the observed factors to the rural-urban disparities in self-medication, thus to inform policy guidance and interventions to improve their training on appropriate medicine use that should lead to changes in behavior, and reduce the rural-urban children health disparities. The objectives of this study were: (1) to examine factors associated with self-medication in a sample of children who lived in China; and (2) to quantify the degree to which disparities could theoretically be reduced if ruralurban differences in determinants of self-medication were eliminated, this study was to apply Oaxaca-Blinder decomposition [24] to explore rural-urban disparities in self-medication among children. 


\section{Methods}

\section{Setting and participants}

A cross-sectional survey was conducted in Chengdu, China between February 2016 and June 2016. The sample was selected using two-stage stratified random sampling. In the first stage, we randomly selected 5 communities from urban areas and 20 townships from rural areas in Chengdu of Sichuan Province. In the second stage, 280 children aged 0-6years were randomly selected from each community, and 80 children aged 0-6years were randomly selected from each township (Fig. 1). The primary caregivers of children selected were asked to respond anonymously during face-to-face interviews by trained interviewers. Primary caregivers were defined as those who regularly cared for the children, such as parents or grandparents [25]. A total of 2798 participants completed the questionnaires in the end, 1262 participants in urban areas with an effective response rate of $90.1 \%$ and 1536 participants in rural areas with an effective response rate of $96.0 \%$. Informed consent was obtained from each primary caregiver following a detail explanation about the purpose of the study.

\section{Measures}

The dependent variable of interest was self-medication of children. Independent variables included 15 measures of characteristics at the children, primary caregivers and household levels.

\section{Self-medication in children}

Primary caregiver's self-medication for children was measured by an affirmative response (Yes) to the question: "Did you give your children medicine without the doctor's permission or advice in prior year?"

\section{Children's characteristics}

Children's characteristics included socio-demographic characteristics, health-related behaviors and health status. The socio-demographic characteristics included gender, age (0-2 and 3-6 years), having medical insurance (yes, no). Health-related behaviors and health status included: having unhealthy eating habits, having chronic diseases, being sick in the 2 weeks prior to the survey, and hospitalized in prior year. The response was "yes" or "no". In this study, unhealthy eating habits were defined as eating habits that adversely affect children's health

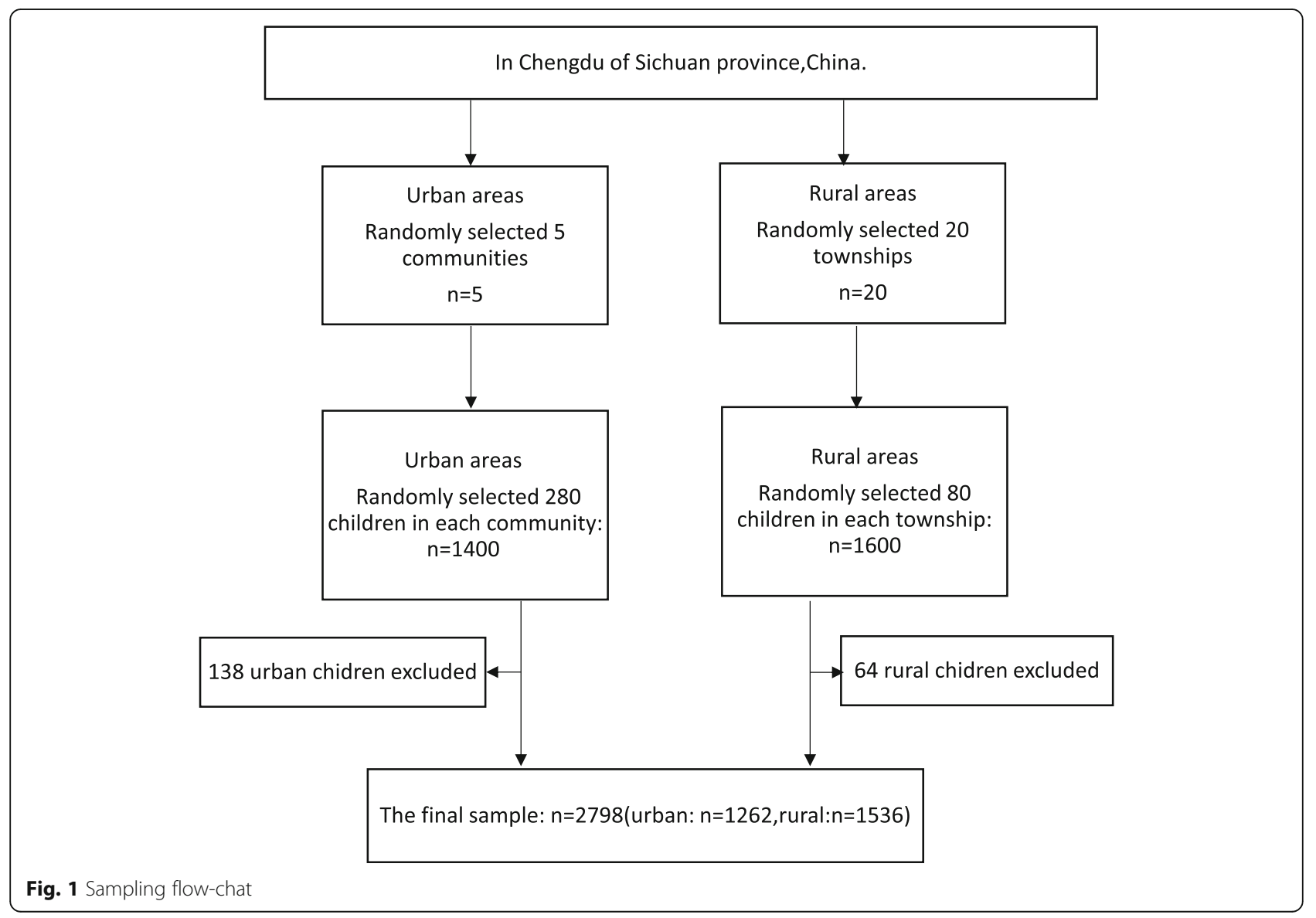


formed in their daily life, such as picky food, partial food, eating more snacks, gluttony, playing or watching $\mathrm{TV}$ while eating.

\section{Primary caregivers' characteristics}

Primary caregivers' characteristics included gender, age $(<=29,30-44,45-59$ and $>=60$ years), education (primary school or below, secondary or high school, college or above), employment (unemployment, nonmanual work, manual work and retirement), primary caregivers often acquire health knowledge (yes or no).

\section{Household-level factors}

Household factors included monthly household income per capita $(<=1000,1001-3000$, and $>3000$ Yuan), and walking time from home to the nearest medical institution $(<=10 \mathrm{~min},>10 \mathrm{~min})$.

\section{Statistical analysis}

Categorical variables were described with frequencies and percentages by rural and urban areas. Chi-square tests were used to evaluate significant differences with respect to categorical variables. We used multivariable logistic regression analysis to examine factors associated with primary caregiver's self-medication of children. To investigate the relative contribution of each of the considered factors, we conducted an OaxacaBlinder decomposition analysis (OBDA) [24]. This is commonly used to analyze differences in continuous dependent variables, but it can be applied to analyze absolute differences in a binary variable such as selfmedication status [26]. OBDA partitions the gap into an "explained" portion and an "unexplained" portion. In this study, the "explained" portion represents the amount by which the rural-urban difference in selfmedication among children would be reduced in the hypothetical world where, other things equal, rural children experienced the same mean levels of measured children, primary caregivers, and household exposures as urban children. Our model specification began with a base model of children-level variables (Model 1) and then sequentially added primary caregivers-level covariates (Model 2) and householdlevel factors (Model 3), to assess the extent to which the rural-urban self-medication in children gaps can be "explained" by these factors. All data was entered into the Epidata Entry software (version 3.1, EpiData Association, Odense, Denmark). Statistical analyses were conducted in STATA version 14. The odds ratio (OR) was reported along with $95 \%$ confidence interval (CI). A $p$-value less than 0.05 was considered to be statistically significant.

\section{Results}

Sample characteristics by rural and urban areas

A summary of the characteristics of 2798 respondents (45.1\% in urban, $54.9 \%$ in rural) are presented in Table 1. Boys in urban and rural areas accounted for 57.2 and $52.1 \%(p=0.007)$. The proportion of children aged $0-2$ years and 3-6 years in urban areas was close (50.8 and $49.2 \%)$, while the majority of children in rural areas (67.0\%) was aged 3-6years. The majority of children participated in medical insurance $(82.1 \%$ in urban and $93.0 \%$ in rural, $p<0.001)$. In urban and rural areas, 31.7 and $45.2 \%$ of children had unhealthy eating habits $(p<$ 0.001 ). There were statistically significant differences between urban and rural areas in children with chronic diseases (5.0 and 2.6\%), being sick in the 2 weeks prior to the survey (4.4 and $21.0 \%)$ and hospitalized in prior year (5.0 and 9.2\%).

The majority of the primary caregivers were female (85.4\% in urban and $88.4 \%$ in rural, $p=0.019$ ), and married $(89.8 \%$ in urban and $92.7 \%$ in rural, $p=0.006)$. In urban and rural areas, the highest proportion of primary caregivers was $45-59$ years old (30.4 and 37.6\%, $p<$ 0.001 ). The highest proportion of primary caregivers' education was secondary school or high school $(58.7 \%$ in urban and $48.5 \%$ in rural, $p<0.001$ ). Over half of primary caregivers in the urban areas (56.9\%) were engaged in nonmanual work, while more than half $(66.4 \%)$ of primary caregivers in the rural areas were engaged in manual work. In urban and rural areas, 54.4 and $33.9 \%$ of primary caregivers often acquired health knowledge, respectively $(p<0.001)$. The highest proportion of monthly household income per capita was more than 3000 Yuan $(50.2 \%)$ in urban areas, while the highest proportion of rural areas was less than 1000 Yuan (78.8\%). More than half of the respondents took less than $10 \mathrm{~min}$ from home to the nearest medical institution $(81.1 \%$ in urban and $54.7 \%$ in rural, $p<0.001$ ).

\section{Prevalence of primary caregivers self-medication for children in urban and rural areas}

Table 2 describes primary caregivers self-medication for children in urban and rural areas. A total of 823 (29.4\%) primary caregivers self-medicated their children. The results showed that $38.2 \%$ primary caregivers in rural areas self-medicated their children, compared to $18.7 \%$ of those in urban areas $(P<0.001)$.

\section{Factors associated with self-medication in children}

Table 3 reports the results of the multivariable logistic regression models predicting the likelihood of selfmedication in children, stratified by rural-urban location.

In urban areas, unhealthy eating habits of children, primary caregivers' education, and the walking time 
Table 1 Characteristics of the study sample: children, primary caregivers, and household in Chengdu of China, stratified, by rural-urban location $(n=2798)$

\begin{tabular}{|c|c|c|c|c|c|}
\hline \multirow[t]{2}{*}{ Characteristics } & \multicolumn{2}{|c|}{ Urban areas } & \multicolumn{2}{|c|}{ Rural areas } & \multirow[b]{2}{*}{$P$ Value } \\
\hline & $\bar{n}$ & $\%$ & $\bar{n}$ & $\%$ & \\
\hline Total & 1262 & 45.1 & 1536 & 54.9 & \\
\hline \multicolumn{6}{|l|}{ Children } \\
\hline Gender & & & & & 0.007 \\
\hline Girls & 540 & 42.8 & 736 & 47.9 & \\
\hline Boys & 722 & 57.2 & 800 & 52.1 & \\
\hline Age (years) & & & & & $<0.001$ \\
\hline $0-2$ & 641 & 50.8 & 507 & 33.0 & \\
\hline $3-6$ & 621 & 49.2 & 1029 & 67.0 & \\
\hline Having medical insurance & & & & & $<0.001$ \\
\hline No & 226 & 17.9 & 107 & 7.0 & \\
\hline Yes & 1036 & 82.1 & 1429 & 93.0 & \\
\hline Children having unhealthy ea & & & & & $<0.001$ \\
\hline No & 862 & 68.3 & 841 & 54.8 & \\
\hline Yes & 400 & 31.7 & 695 & 45.2 & \\
\hline Children with chronic disease & & & & & 0.001 \\
\hline No & 1199 & 95.0 & 1496 & 97.4 & \\
\hline Yes & 63 & 5.0 & 40 & 2.6 & \\
\hline \multicolumn{2}{|c|}{ Children being sick in the 2 weeks prior to the survey } & & & & $<0.001$ \\
\hline No & 1207 & 95.6 & 1213 & 79.0 & \\
\hline Yes & 55 & 4.4 & 323 & 21.0 & \\
\hline Children hospitalized in prior & & & & & $<0.001$ \\
\hline No & 1199 & 95.0 & 1395 & 90.8 & \\
\hline Yes & 63 & 5.0 & 141 & 9.2 & \\
\hline \multicolumn{6}{|l|}{ Primary caregivers } \\
\hline Gender & & & & & 0.019 \\
\hline Female & 1078 & 85.4 & 1358 & 88.4 & \\
\hline Male & 184 & 14.6 & 178 & 11.6 & \\
\hline Age (years) & & & & & $<0.001$ \\
\hline$<=29$ & 199 & 15.8 & 314 & 20.4 & \\
\hline $30--44$ & 347 & 27.5 & 327 & 21.3 & \\
\hline $45--59$ & 384 & 30.4 & 577 & 37.6 & \\
\hline$>=60$ & 332 & 26.3 & 318 & 20.7 & \\
\hline Education & & & & & $<0.001$ \\
\hline Primary school or below & 283 & 22.4 & 697 & 45.4 & \\
\hline Secondary or High school & 741 & 58.7 & 745 & 48.5 & \\
\hline College or above & 238 & 18.9 & 94 & 6.1 & \\
\hline Occupation & & & & & $<0.001$ \\
\hline Unemployment & 330 & 26.1 & 214 & 13.9 & \\
\hline Nonmanual work & 718 & 56.9 & 250 & 16.3 & \\
\hline Manual work & 16 & 1.3 & 1020 & 66.4 & \\
\hline Retirement & 198 & 15.7 & 52 & 3.4 & \\
\hline Marital status & & & & & 0.006 \\
\hline
\end{tabular}


Table 1 Characteristics of the study sample: children, primary caregivers, and household in Chengdu of China, stratified, by rural-urban location $(n=2798)$ (Continued)

\begin{tabular}{|c|c|c|c|c|c|}
\hline \multirow[t]{2}{*}{ Characteristics } & \multicolumn{2}{|c|}{ Urban areas } & \multicolumn{2}{|c|}{ Rural areas } & \multirow[b]{2}{*}{$P$ Value } \\
\hline & $\mathrm{n}$ & $\%$ & $\mathrm{n}$ & $\%$ & \\
\hline Single & 129 & 10.2 & 112 & 7.3 & \\
\hline Married & 1133 & 89.8 & 1424 & 92.7 & \\
\hline \multicolumn{2}{|c|}{ Primary caregivers often acquire health knowledge } & & & & $<0.001$ \\
\hline No & 575 & 45.6 & 1015 & 66.1 & \\
\hline Yes & 687 & 54.4 & 521 & 33.9 & \\
\hline \multicolumn{6}{|l|}{ Household } \\
\hline \multicolumn{2}{|c|}{ Monthly household income per capita, Yuan } & & & & $<0.001$ \\
\hline$<=1000$ & 90 & 7.1 & 1211 & 78.8 & \\
\hline $1001-3000$ & 539 & 42.7 & 316 & 20.6 & \\
\hline$>3000$ & 633 & 50.2 & 9 & 0.6 & \\
\hline \multicolumn{3}{|c|}{ Walking time from home to the nearest medical institution } & & & $<0.001$ \\
\hline$<=10 \mathrm{~min}$ & 1024 & 81.1 & 840 & 54.7 & \\
\hline$>10 \mathrm{~min}$ & 238 & 18.9 & 696 & 45.3 & \\
\hline
\end{tabular}

from home to the nearest medical institution were significantly associated with the self-medication in children. Children having unhealthy eating habits $(\mathrm{OR}=2.01,95 \%$ CI: $1.47-2.76)$ were more likely to have been selfmedicated by their primary caregivers. And primary caregivers with college or above education $(\mathrm{OR}=2.01$, 95\%CI: $1.17-3.45)$, who spent more than $10 \mathrm{~min}$ from home to the nearest medical institution $(\mathrm{OR}=1.81$, 95\%CI: $1.27-2.56)$ were more likely to self-medicate their children.

In rural areas, children's age, unhealthy eating habits of children, children suffering from chronic diseases, primary caregiver's age, primary caregiver's education, and monthly household income per capita were significantly associated with the self-medication in children. Primary caregivers were more likely to self-medicate their children aged 3-6 years (OR $=1.51,95 \% \mathrm{CI}: 1.18-1.94)$, having unhealthy eating habits $(\mathrm{OR}=1.86,95 \% \mathrm{CI}$ : 1.49 $2.32)$, and suffering from chronic diseases $(\mathrm{OR}=1.99$, 95\%CI: 1.01-3.89). Primary caregivers who over the age of $60(\mathrm{OR}=0.57,95 \% \mathrm{CI}: 0.38-0.86)$, with college or above education $(\mathrm{OR}=0.42,95 \% \mathrm{CI}: 0.23-0.78)$ were less likely to self-medicate their children. And primary caregivers with monthly household income per capita of

Table 2 Primary caregivers self-medication for children in urban and rural areas

\begin{tabular}{|c|c|c|c|c|c|c|}
\hline \multirow{2}{*}{$\begin{array}{l}\text { Self- } \\
\text { medication }\end{array}$} & \multicolumn{2}{|c|}{ Urban children } & \multicolumn{2}{|c|}{ Rural children } & \multirow[t]{2}{*}{$x^{2}$} & \multirow{2}{*}{$\begin{array}{l}p \text { - } \\
\text { value }\end{array}$} \\
\hline & $\bar{n}$ & $\%$ & $\bar{n}$ & $\%$ & & \\
\hline Yes & 236 & 18.7 & 587 & 38.2 & 127.086 & $<0.001$ \\
\hline No & 1026 & 81.3 & 949 & 61.8 & & \\
\hline
\end{tabular}

1001-3000 (OR =1.42, 95\% CI:1.07-1.88) were more likely to self-medicate their children.

\section{Decomposing rural-urban disparities in self-medication among children}

The respective contributions of the children, primary caregivers and household factors to the "explained" part of the self-medication gap in children are showed in Table 4.

The results showed that the base model (Model 1) included only the children characteristics explained $18.32 \%$ of rural-urban self-medication gap in children. Once primary caregivers' variables were included, the explained portion of self-medication gap in children increased to $19.86 \%$ (Model 2). Adding the household covariates, the explained portion of self-medication gap in children increased to $32.01 \%$ (Model 3). In the full model (Model 3), children variables explained the largest portion of the rural-urban self-medication gap, approximately $18.54 \%$.

The predicted rural-urban difference in probability of self-medication among children was 0.195 (95\% CI: $0.163,0.228)$. Children's age and children having unhealthy eating habits were significant factors in the decomposition model 3. And these two variables contributed positively to the modeled rural-urban gap. Unhealthy eating habits of children were the largest contributor to the part of the inequality deriving from differences in group characteristics. The rural-urban selfmedication gap in children would be reduced by 9.14 and $6.52 \%$, respectively, if children in rural areas had the same rate of unhealthy eating habits and age distribution as those in urban areas. 
Table 3 Multivariable logistic regression analysis of factors associated with primary caregivers self-medication for children in urban and rural areas $(n=2798)$

\begin{tabular}{|c|c|c|c|c|}
\hline \multirow[t]{2}{*}{ Variables } & \multicolumn{2}{|c|}{ Urban areas } & \multicolumn{2}{|c|}{ Rural areas } \\
\hline & $\overline{\mathrm{OR}}$ & $95 \% \mathrm{Cl}$ & $\overline{\mathrm{OR}}$ & $95 \% \mathrm{Cl}$ \\
\hline \multicolumn{5}{|l|}{ Children } \\
\hline Boys (ref: Girls) & 1.15 & $0.85-1.55$ & 0.99 & $0.80-1.22$ \\
\hline Age (years) (ref: 0-2) & 1.36 & $0.98-1.87$ & $1.51^{* *}$ & $1.18-1.94$ \\
\hline \multicolumn{5}{|l|}{ Medical insurance (ref: No insurance) } \\
\hline Social & 0.84 & $0.56-1.26$ & 0.94 & $0.61-1.46$ \\
\hline Commercial & 1.36 & $0.52-3.59$ & 2.56 & $0.80-8.21$ \\
\hline Social and commercial & 1.29 & $0.79-2.11$ & 1.00 & $0.57-1.75$ \\
\hline Children have unhealthy eating habits (ref: No) & $2.01^{* * *}$ & $1.47-2.76$ & $1.86^{* * *}$ & $1.49-2.32$ \\
\hline Suffering from chronic diseases (ref: No) & 0.64 & $0.25-1.69$ & $1.99^{*}$ & $1.01-3.89$ \\
\hline Have been hospitalized in the past year (ref: No) & 1.40 & $0.75-2.62$ & 1.06 & $0.73-1.55$ \\
\hline \multicolumn{5}{|l|}{ Primary Caregivers } \\
\hline Male (ref: Female) & 0.99 & $0.65-1.51$ & 1.18 & $0.84-1.66$ \\
\hline \multicolumn{5}{|l|}{ Age (years) (ref: <=29) } \\
\hline $30--44$ & 0.91 & $0.58-1.43$ & 1.01 & $0.72-1.42$ \\
\hline $45--50$ & 0.74 & $0.47-1.17$ & 0.75 & $0.54-1.05$ \\
\hline$>=60$ & 0.72 & $0.45-1.14$ & $0.57^{* *}$ & $0.38-0.86$ \\
\hline \multicolumn{5}{|l|}{ Education level (ref: Primary school or below) } \\
\hline Secondary and High school & 1.39 & $0.93-2.07$ & 0.82 & $0.63-1.07$ \\
\hline College or above & $2.01^{*}$ & $1.17-3.45$ & $0.42^{* *}$ & $0.23-0.78$ \\
\hline \multicolumn{5}{|l|}{ Occupation (ref: Unemployment) } \\
\hline Nonmanual work & 0.93 & $0.64-1.34$ & 0.99 & $0.65-1.53$ \\
\hline Manual work & 1.04 & $0.22-4.93$ & 1.26 & $0.90-1.76$ \\
\hline Retirement & 0.66 & $0.39-1.11$ & 1.32 & $0.68-2.56$ \\
\hline Married (ref: Single) & 1.01 & $0.61-1.67$ & 1.00 & $0.66-1.51$ \\
\hline Primary caregivers often acquire health knowledge (ref: No) & 1.07 & $0.79-1.45$ & 1.04 & $0.82-1.32$ \\
\hline \multicolumn{5}{|l|}{ Household } \\
\hline \multicolumn{5}{|l|}{ Monthly household income per person (RMB), yuan (ref: <=1000) } \\
\hline $1001-3000$ & 1.04 & $0.59-1.84$ & $1.42^{*}$ & $1.07-1.88$ \\
\hline$>3000$ & 0.58 & $0.31-1.06$ & 0.36 & $0.04-3.00$ \\
\hline More than 10 min walk from home to the nearest medical institution (ref: $<=10 \mathrm{~min}$ ) & $1.81^{* *}$ & $1.27-2.56$ & 0.96 & $0.77-1.19$ \\
\hline
\end{tabular}

Notes: ${ }^{*} p<0.05 ; * * 0<01 ; * * *<0.001$

\section{Discussion}

This study is to examine the potential factors associated with self-medication in children. At the same time, this study is the first to explore the potential contribution of children, primary caregivers and household factors to the rural-urban disparities in self-medication among children, and to propose alternative strategies to reduce the rural-urban disparities.

This study found that the rate of primary caregivers self-medication for children in rural areas (38.2\%) was higher than that in urban areas (18.7\%). These possible reasons may be responsible for the situation in China. One is that prescription medicine management in rural areas is less strict than urban places, and prescriptions might be easier to obtain [27]. The other is that rural residents are usually far away from health facilities, or their families are poor [28], may force them to use leftovers from previous prescriptions or bought at pharmacy to treat their children health disorders [29].

This study found that the education of primary caregivers was the common factor influencing the selfmedication among urban and rural children. Urban primary caregivers with college or above education were more likely to self-medicate their children. It was similar to the previous studies found that well-educated primary caregivers preferred to use medicine for their children 
Table 4 Predicted probability and disparity in self-medication between rural and urban children, and percentage of the difference explained by children, primary caregivers, and household variables

\begin{tabular}{|c|c|c|c|}
\hline & \multicolumn{3}{|c|}{ Rural children vs. Urban children } \\
\hline & $\begin{array}{r}\text { Model } 1 \\
\text { Mean((95\%Cl) }\end{array}$ & $\begin{array}{c}\text { Model } 2 \\
\text { Mean }((95 \% \mathrm{Cl})\end{array}$ & $\begin{array}{c}\text { Model } 3 \\
\text { Mean((95\%Cl) }\end{array}$ \\
\hline \multicolumn{4}{|l|}{ Predicted probability } \\
\hline Rural children & $0.382(0.358,0.406) * * *$ & $0.382(0.358,0.406)^{* * *}$ & $0.382(0.358,0.406)^{* * *}$ \\
\hline Urban children & $0.187(0.165,0.209) * * *$ & $0.187(0.165,0.209) * * *$ & $0.187(0.165,0.209) * * *$ \\
\hline Rural-urban disparity & $0.195(0.163,0.228) * * *$ & $0.195(0.163,0.228)^{* * *}$ & $0.195(0.163,0.228) * * *$ \\
\hline Percent difference explained & Contribution & Contribution & Contribution \\
\hline Total difference explained (\%) & $18.32^{* * *}$ & $19.86^{* * *}$ & $32.01^{* *}$ \\
\hline Children (\%) & $18.32^{* * *}$ & $18.48^{* * *}$ & $18.54^{* * *}$ \\
\hline Gender & -0.17 & -0.19 & -0.19 \\
\hline Age (years) & $6.25^{* * *}$ & $6.55^{* * *}$ & $6.52^{* * *}$ \\
\hline Medical insurance & -0.95 & -0.98 & -0.76 \\
\hline Children having unhealthy eating habits & $9.02^{* * *}$ & $9.16^{* * *}$ & $9.14^{* * *}$ \\
\hline Children with chronic diseases & -0.22 & -0.29 & -0.32 \\
\hline Children being sick in the 2 weeks prior to the survey & 3.66 & 3.53 & 3.48 \\
\hline Children hospitalized in prior year & 0.73 & 0.70 & 0.67 \\
\hline Primary caregivers (\%) & & 1.38 & 0.46 \\
\hline Gender & & -0.20 & -0.18 \\
\hline Age (years) & & 0.87 & 0.93 \\
\hline Education & & 0.24 & -0.49 \\
\hline Occupation & & 0.69 & 0.57 \\
\hline Material status & & 0.14 & 0.13 \\
\hline Primary caregivers often acquire health knowledge & & -0.36 & -0.50 \\
\hline Household (\%) & & & 13.02 \\
\hline Monthly household income per capita, Yuan & & & 9.21 \\
\hline Walking time from home to the nearest medical institution & & & 3.81 \\
\hline
\end{tabular}

Notes: ${ }^{*} p<0.05 ;{ }^{* *} p<0.01 ; * * * 0<0.001$

themselves without seeing doctors [7, 13]. In contrast to urban areas, rural primary caregivers with college or above education were less likely to self-medicate their children. A previous study also indicated that primary caregivers with lower levels of education were more likely to self-medicate their children [30]. This is an interesting paradox that suggests the higher educational level of primary caregivers is a risk factor for selfmedication among urban children but a protective factor for self-medication among rural children in China. The influencing mechanism of the primary caregivers' education on self-medication among children in different regions is worth noting for future research. Unhealthy eating habits of children were also the common enabling factor for primary caregivers self-medication for children in urban and rural areas. Unhealthy eating habits could lead to nutritional imbalance, and thus lead to a decline in children's health [31]. A previous study found that poor health condition of children was a strong predictor of self-medication in children [32].

In urban areas, walking time from home to the nearest institution was another influential factor which impacted on primary caregivers self-medication for children. In this study, urban primary caregivers who spend more than $10 \mathrm{~min}$ from home to the nearest medical institution were more likely to self-medicate their children. Self-medication means lower utilization of medical services. M. Bayham' study reported that longer travel time to a health facility was associated with decreased utilization of medical services [33].

In rural areas, children's age, primary caregivers' age, and the monthly household income per capita were another set of influential factors which impacted on primary caregivers self-medication for children. Primary caregivers were more likely to self-medicate their children who aged 3-6 years. It was similar to a national 
survey in China, which showed that the proportion of guardians using antibiotics without doctors' prescription for their children was getting higher with the age of children increases [5]. P. Bi's study also showed that mothers might become less protective, self-medication and even medicine abuse when the children grow up [13]. The primary caregivers who over the age of 60 years were less likely to self-medicate their children compared with those under the age of 29 years. It was in accordance with some studies identified younger age of primary caregivers to be significantly associated with the increased antibiotic use in self-medication [34-36]. The monthly household income per capita was also a factor influencing the self-medication of rural children. The primary caregivers with monthly household income per capita of 1001-3000 Yuan were more likely to selfmedicate their children than those with less than 1000 Yuan. It is possible that they could afford to buy medicine from pharmacies, but have difficulty in affording to visit physicians [37].

In addition, rural primary caregivers were more likely to self-medicate their children suffering from chronic diseases. Hoai et al. also found that chronic disease was positively associated with the frequency of selfmedication [38].

R. Li's study showed that the prevalence of antibiotic use without doctors' prescription in boys was higher than that in girls in Western and Eastern China, and primary caregivers having basic health knowledge were protective factors of antibiotic in self-medication among children 0-6 years with diarrhea in China [5]. But this study found children's gender and primary caregivers often acquire health knowledge were not associated with primary caregivers self-medication for children in urban and rural areas.

This study provides new insight into sources of selfmedication disparities by utilizing an econometric technique that has been applied to study disparities in other social and economic issues. We found that children, primary caregivers and household variables helped explained $32.01 \%$ of the rural-urban self-medication gap in children.

Children variables explained the largest portion of the rural-urban self-medication gap in children. Unhealthy eating habits of children were the largest contributor to the part of the inequality deriving from differences in group characteristics. Characteristics analysis also showed that the rate of unhealthy eating habits in the rural areas was significantly greater than that in the urban areas $(45.2 \% \mathrm{vs} .31 .7 \%, P<0.001)$. And multivariable logistic analysis found that primary caregivers were more likely to self-medicate their children having unhealthy eating habits. Another factor contributing to the children rural-urban self-medication gap was children's age. The odds of children's self-medication in aged 3-6 years was greater than those who were aged $0-2$ years. Since the children's self-medication is determined by the primary caregivers, educational programs and public campaigns should be considered by health care authorities in order to ensure the primary caregivers to recognize the dangers of self-medication for children and the importance of a balanced diet to children's health.

The relative strength and weakness must be taken into account when interpreting the findings of our study. This is the first study to examine the contribution of children, primary caregivers and household factors to the rural-urban differences in self-medication among children, which is conducive to reduce the rural-urban inequity. Our study is also strengthened by our methodology using face-to-face interviews which increases the precision of information obtained. However, it also has some limitations. This study is the cross-sectional study design which does not allow for determination of causality. In addition, this study lacks the survey of factors such as health belief and health literacy of primary caregivers, which may be related to self-medication in children [39].

\section{Conclusion}

This study found that the rate of primary caregivers selfmedicated their children in rural areas (38.2\%) was higher than that in urban areas (18.7\%). Unhealthy eating habits of children were the largest contributor to the rural-urban self-medication inequality in children. The evidence presented in this study increasingly suggests that public health policies addressing rural-urban differences in children's factors could serve as an effective method for reducing rural-urban disparities in selfmedication among children, and therefore, reducing long-term differences in health outcomes later in life. Educational programs and public campaigns should be considered by health care authorities in order to ensure the primary caregivers to recognize the dangers of selfmedication for children. As the findings reported, a substantial portion of rural-urban differences in selfmedication among children remained unexplained by the uneven distributions of the above factors between rural areas and urban areas. Therefore, future research is strongly recommended to identify and assess the contribution of each unknown factor.

\section{Acknowledgments}

The authors wish to acknowledge all investigators who contributed to data collection, and also thankful to all primary caregivers who participated in this study.

\section{Authors' contributions}

DP-L led the conception, design, and coordination of the study. JJ-G drafted the manuscript, and JJ-G and XX-S conducted the analysis. DP-L, HD-M and 
PG-R revised the manuscript critically for important intellectual content. The author(s) read and approved the final manuscript.

\section{Funding}

No funding.

\section{Availability of data and materials}

The datasets generated and/or analysed during the current study are available in the figshare repository, https://doi.org/10.6084/m9.figshare. 12416363

\section{Declarations}

\section{Ethics approval and consent to participate}

The study protocol was approved by the Institutional Review Board of Sichuan University. Informed consent was obtained from primary caregivers as they and children are involved in the study following a detail explanation about the purpose of the study. Participation in the study was voluntary and anonymous, and participants' information was kept completely confidential. All methods were carried out in accordance with relevant guidelines and regulations.

\section{Consent for publication}

Not applicable.

\section{Competing interests}

The authors declare that they have no competing interests.

\section{Author details}

'Department of Health Related Behavior and Social Medicine, West China School of Public Health and West China Fourth Hospital, Sichuan University, Chengdu, China. ${ }^{2}$ Gansu Provincial Maternity and Child-care Hospital, Lanzhou, China. ${ }^{3}$ West China Second University Hospital, Sichuan University/ West China Women's and Children's Hospital, Chengdu, China. ${ }^{4}$ School of Aging Studies, College of Behavioral \& Community Sciences, University of South Florida, Tampa, FL 33620, USA

Received: 21 March 2021 Accepted: 7 October 2021

Published online: 18 November 2021

\section{References}

1. Niclós G, Olivar T, Rodilla V. Factors associated with self-medication in Spain: a cross-sectional study in different age groups. Int J Pharm Pract. 2018;26(3): 258-66. https://doi.org/10.1111/ijpp.12387.

2. Pereira F, Bucaretchi F, Stephan C, Cordeiro R. Self-medication in children and adolescents. J Pediatr. 2007;83(5):453-8. https://doi.org/10.2223/JPED.1 703.

3. Alili-Idrizi E, Dauti M, Malaj L. Validation of the parental knowledge and attitude towards antibiotic usage and resistance among children in Tetovo, the republic of Macedonia. Pharm Pract. 2014;12(4):467. PubMed PMID: 25580168; PubMed Central PMCID: PMC4282763. https://doi.org/10.4321/S1 886-36552014000400003.

4. Yu M, Zhao G, Stalsby Lundborg C, Zhu Y, Zhao Q, Xu B. Knowledge, attitudes, and practices of parents in rural China on the use of antibiotics in children: a cross-sectional study. BMC Infect Dis. 2014;14(1):112. https://doi org/10.1186/1471-2334-14-112. PubMed PMID: 24576064; PubMed Central PMCID: PMC3938908.

5. Li R, Xiao F, Zheng $X$, Yang $H$, Wang $L$, Yin D, et al. Antibiotic misuse among children with diarrhea in China: results from a national survey. PeerJ. 2016;4: e2668. https://doi.org/10.7717/peerj.2668.

6. Ylinen S, Hämeen-Anttila K, Sepponen K, Lindblad A, Ahonen R. The use of prescription medicines and self-medication among children--a populationbased study in Finland. Pharmacoepidemiol Drug Saf. 2010;19(10):1000-8. https://doi.org/10.1002/pds.1963.

7. Du Y, Knopf H. Self-medication among children and adolescents in Germany: results of the National Health Survey for children and adolescents (KiGGS). Br J Clin Pharmacol. 2009;68(4):599-608. https://doi.org/10.1111/j.13 65-2125.2009.03477.x.

8. Chang J, Wang Q, Fang Y. Socioeconomic differences in self-medication among middle-aged and older people: data from the China health and retirement longitudinal study. BMJ Open. 2017;7(12):e017306. https://doi org/10.1136/bmjopen-2017-017306.

9. Chang J, Ye D, Lv B, Jiang M, Zhu S, Yan K, et al. Sale of antibiotics without a prescription at community pharmacies in urban China: a multicentre cross-sectional survey. J Antimicrobial Chemother. 2017;72(4):dkw519.

10. Fang Y. China should curb non-prescription use of antibiotics in the community. BMJ. 2014;348(348):g4233. https://doi.org/10.1136/bmj.g4233.

11. Guo L, Xu Y, Deng J, He Y, Gao X, Li P, et al. Non-medical use of prescription pain relievers among high school students in China: a multilevel analysis. BMJ Open. 2015;5(7):e007569. https://doi.org/10.1136/ bmjopen-2014-007569.

12. Yu C, Liu E, Dai Z. Reproductive equity, population quality and China's comprehensive policy of encouraging two children. J Demography. 2017; 03(39):5-19.

13. Bi $\mathrm{P}$, Tong S, Parton K. Family self-medication and antibiotics abuse for children and juveniles in a Chinese city. Soc Sci Med. 2000;50(10):1445-50. https://doi.org/10.1016/S0277-9536(99)00304-4.

14. Toska A, Geitona M. Antibiotic resistance and irrational prescribing in paediatric clinics in Greece. Br J Nurs. 2015;24(1):28-33. https://doi.org/10.12 968/bjon.2015.24.1.28.

15. Harvie M. Nutritional supplements and cancer: potential benefits and proven harms. Am Soc Clin Oncol Educ Book Am Soc Clin Oncol Meet. 2014:e478-86. https://doi.org/10.14694/EdBook_AM.2014.34.e478 PubMed PMID: 24857143

16. Rolfe HM. A review of nicotinamide: treatment of skin diseases and potential side effects. J Cosmet Dermatol. 2014;13(4):324-8. https://doi.org/1 0.1111/jocd.12119 PubMed PMID: 25399625

17. Ng AWT, Poon SL, Huang MN, Lim JQ, Boot A, Yu W, et al. Aristolochic acids and their derivatives are widely implicated in liver cancers in Taiwan and throughout Asia. Sci Transl Med. 2017;9(412). https://doi.org/10.1126/scitra nslmed.aan6446 PubMed PMID: 29046434.

18. IC W, AJ N. A literature review to identify interventions to improve the use of medicines in children.\%a Costello I. Child Care Health Dev. 2004;30(6): 647-65.

19. Schaefer MK, Shehab N, Cohen AL, et al. Adverse events from cough and cold medications in children. Pediatrics. 2008;121(4):783-7.

20. Rimsza ME, Newberry S. Unexpected infant deaths associated with use of cough and cold medications. Pediatrics. 2008;122(2):e318-22.

21. Stewart Williams J, Norstrm F, Ng N. Disability and ageing in China and India - decomposing the effects of gender and residence. Results from the WHO study on global AGEing and adult health (SAGE). BMC Geriatr. 2017; 17(1):197.

22. Li J, Shi L, Li S, Xu L, Qin W, Wang H. Urban-rural disparities in hypertension prevalence, detection, and medication use among Chinese Adults from 1993 to 2011. International Journal for Equity in Health. 2017;16(1):50.

23. Farah R, Lahoud N, Salameh P, Saleh N. Antibiotic dispensation by Lebanese pharmacists: a comparison of higher and lower socio-economic levels. J Infect Public Health. 2015;8(1):37-46. https://doi.org/10.1016/j.jiph.2014.07.003.

24. Benmarhnia T, Huang J, Basu R, Wu J, Bruckner TA. Decomposition analysis of black-white disparities in birth outcomes: the relative contribution of air pollution and social factors in California. Environ Health Perspect. 2017; 125(10):107003.

25. Tang A, Ji M, Zhang Y, Zou J, Li M, Yang L, et al. Dietary behaviors and caregiver perceptions of overweight and obesity among Chinese preschool children. Int J Environ Res Public Health. 2018;15(4):716.

26. Fortin NM, Lemieux T, Firpo S. Decomposition methods in economics. Handb Labor Econ. 2011;4a(16045):1-102.

27. Wu Q, Yu J, Yang C, Chen J, Yang L, Zhang H, et al. Nonmedical use of cough syrup among secondary vocational school students. Medicine. 2016; 95(10):e2969.

28. Zewdie T, Azale T, Shimeka A, Lakew AM. Self-medication during pregnancy and associated factors among pregnant women in Goba town, Southeast Ethiopia: a community based cross sectional study. BMC Research Notes. 2018;11(1):713.

29. Papakosta M, Zavras D, Niakas D. Investigating factors of self-care orientation and self-medication use in a Greek rural area. Rural Remote Health. 2014;14:2349.

30. Jamhour A, El-Kheir A, Salameh P, Hanna P, Mansour H. Antibiotic knowledge and self-medication practices in a developing country: a crosssectional study. Am J Infect Control. 2017:45(4):384-8. https://doi.org/10.101 6/j.ajic.2016.11.026. 
31. Chatoor I, Ganiban J, Surles J, Doussardroosevelt J. Physiological regulation and infantile anorexia: a pilot study. J Am Acad Child Adolesc Psychiatry. 2004;43(8):1019-25. https://doi.org/10.1097/01.chi.0000126977.64579.4e.

32. Siponen S, Ahonen R, Kiviniemi V, Hämeen-Anttila K. Association between parental attitudes and self-medication of their children. Int J Clin Pharm. 2013;35(1):113-20. https://doi.org/10.1007/s11096-012-9715-2.

33. Bayham M, Blevins M, Lopez M, Olupona O, González-Calvo L, Ndatimana E, et al. Predictors of health-care utilization among children 6-59 months of age in Zambézia Province, Mozambique. Am J Trop Med Hyg. 2017;96(2): 493-500. https://doi.org/10.4269/ajtmh.16-0233.

34. Napolitano F, Izzo M, Di Giuseppe G, Angelillo I. Public knowledge, attitudes, and experience regarding the use of antibiotics in Italy. PLoS One. 2013; 8(12):e84177. https://doi.org/10.1371/journal.pone.0084177.

35. Fernandes M, Leite A, Basto M, Nobre M, Vieira N, Fernandes R, et al. Nonadherence to antibiotic therapy in patients visiting community pharmacies. Int J Clin Pharm. 2014;36(1):86-91. https://doi.org/10.1007/s1 1096-0139850-4.

36. Awad A, Eltayeb I, Matowe L, Thalib L. Self-medication with antibiotics and antimalarials in the community of Khartoum State, Sudan. J Pharm Pharm Sci. 2005;8(2):326-31.

37. Sawair F, Baqain Z, Abu Karaky A, Abu ER. Assessment of self-medication of antibiotics in a Jordanian population. Med Princ Pract. 2009;18(1):21-5. https://doi.org/10.1159/000163041.

38. Hoai $N$, Dang T. The determinants of self-medication: evidence from urban Vietnam. Soc Work Health Care. 2017;56(4):260-82. https://doi.org/10.1080/ 00981389.2016 .1265632

39. Salm F, Ernsting C, Kuhlmey A, Kanzler M, Gastmeier P, Gellert P. Antibiotic use, knowledge and health literacy among the general population in Berlin, Germany and its surrounding rural areas. PLoS One. 2018;13(2):e0193336. https://doi.org/10.1371/journal.pone.0193336.

\section{Publisher's Note}

Springer Nature remains neutral with regard to jurisdictional claims in published maps and institutional affiliations.

Ready to submit your research? Choose BMC and benefit from:

- fast, convenient online submission

- thorough peer review by experienced researchers in your field

- rapid publication on acceptance

- support for research data, including large and complex data types

- gold Open Access which fosters wider collaboration and increased citations

- maximum visibility for your research: over $100 \mathrm{M}$ website views per year

At $\mathrm{BMC}$, research is always in progress.

Learn more biomedcentral.com/submissions 